\title{
A longitudinal study of physical activity and menstrual cycle characteristics in healthy Norwegian women - The Nord-Trøndelag Health Study
}

\author{
Sigridur Lara Gudmundsdottir ${ }^{1}$, William Dana Flanders ${ }^{2}$ and Liv Berit Augestad ${ }^{1}$ \\ 1) Department of Human Movement Science, Faculty of Social Sciences and Technology Management, \\ Norwegian University of Science and Technology (NTNU), 7491 Trondheim, Norway \\ 2) Departments of Epidemiology and Biostatistics, Emory University, Atlanta, GA 30345, USA \\ Correspondence: Sigridur Lara Gudmundsdottir, Department of Human Movement Science, Faculty of Social Sciences and \\ Technology Management, Norwegian University of Science and Technology, NO-7491 Trondheim, Norway \\ E-mail: sigridur.gudmundsdottir@svt.ntnu.no Telephone: +47-7359-1780 Telefax: 47-7359-1770
}

\begin{abstract}
Background: Long menstrual cycles have been associated with anovulation, infertility and spontaneous abortion. Elite athletes have been found at risk of menstrual dysfunction. We evaluated the longitudinal association between leisure time physical activity (LTPA) and menstrual function in healthy non-athletic women.

Methods: A population-based health survey (HUNT 1) was conducted during 1984-1986 in Nord-Trøndelag county, Norway, with follow-up in 1995-1997 (HUNT 2). The current study included 3,097 women, $<45$ years old in HUNT 2. LTPA was assessed by questionnaire in HUNT 1, and menstrual function by questionnaire in HUNT 2. Data focused on overall occurrence of menstrual disorders in the population. Results were adjusted for age, education, psychological health, smoking and alcohol intake. Additional analyses included BMI as a potential confounder.

Results: The median cycle length was 30 days and median number of days bleeding was 5 . In women with normal cycle length, mean (SD) cycle length and duration of bleeding was 29.3 (2.8) and 5.6 (1.7) respectively. Cycle length increased with higher frequency of LTPA for women $>25$ years old. Women, 20-25 years old at baseline who were active most days had increased odds of short cycles, more bleeding days and increased odds of having irregular cycles, $\mathrm{OR}=4.7 ; 95 \% \mathrm{CI}=1.2-18.0$ ). Number of bleeding days decreased with longer duration $(p<0.05)$ and higher intensity $(p=0.065)$ in young women. Adjustment for BMI did not affect the results.
\end{abstract}

Conclusion: Leisure time physical activity may affect menstrual function, although in our study, the results were modified by age.

\section{INTRODUCTION}

Menstrual dysfunction may be an important indicator of altered ovarian function and has been associated with increased risk of diseases such as breast and ovarian cancer, diabetes, cardiovascular disease and fractures (1-5). Shortened follicular phases, manifested in short menstrual cycles (6), have been associated with reduced fecundity $(7,8)$ and spontaneous abortion (9) while irregular or long menstrual cycles relate to anovulation, infertility and spontaneous abortion (6,911). Several lifestyle related factors, including high or low body mass index (BMI) or body weight (11-15) smoking $(11,14)$, alcohol consumption (16), recent oral contraceptive use (17), marijuana use (18), and stress (19-21) have been suggested to affect menstrual cycle length. Heavy caffeine consumption has sometimes but not always been related to increased risk of short menstrual cycles $(18,22)$.

Female elite athletes have repeatedly been found at increased risk of menstrual dysfunction, such as secondary amenorrhea, oligomenorrhea and anovulatory cycles, compared with non-athletes $(23,24)$. These observa- tions have been related to alternations in energy balance in part due to excessive exercise (25-27). The effects of less extreme activity levels, such as those more commonly seen in the general population, are not as well documented. We are only aware of a few published studies. These have suggested that increased frequency and intensity of physical activity are associated with longer menstrual cycles, fewer days of menstrual bleeding and lower risk of irregular cycles (12-14,16,28, 29). However, the great disparity in the terminology used to describe menstrual cycle characteristics and physical activity make study comparisons difficult.

There is abundance of research available regarding the positive effects of regular physical activity for numerous health outcomes (30-32). The potential effect of leisure time physical activity on menstrual function has however not been widely studied and needs further investigation.

The aim of this study is to evaluate the longitudinal association between leisure time physical activity and menstrual cycle length and regularity in healthy, Norwegian women participating in the Nord-Trøndelag Health survey. 


\section{MATERIALS AND METHODS}

\section{Study population}

During the years 1984-1986, all residents of NordTrøndelag county in mid-Norway, men and women aged $\geq 20$ years, were invited to participate in the Nord-Trøndelag Health survey (HUNT 1) and in 19951997 to participate in a follow up survey (HUNT 2).

Both surveys included questionnaires, health examinations and measurements of height and weight at a screening station. In HUNT 1, 74,977 (88.1\%) of those eligible returned a health questionnaire and received a health examination. Of those, 39,393 were women.

In total 34,950 women participated in HUNT 2. Assessments at the screening station included a detailed questionnaire evaluating medication use, menstrual cycle characteristics, reproductive history and gynaecological surgery.

\section{Subjects}

In total, 24,837 women participated in both HUNT 1 and HUNT 2. Of those, 5,986 women were $<45$ years old at HUNT 2, and therefore considered premenopausal. For the prospective analyses we excluded women $(n=2,889)$ who reported serious conditions or diagnoses known to affect capability for physical activity in HUNT 1 or conditions or diagnoses known to affect the menstrual cycle in HUNT 2, or with necessary information missing, as summarized in Figure 1. Women who had given birth during the same year as they participated in HUNT $2(n=99)$ or breastfed within six months of HUNT $2(n=267)$ were excluded from the analysis as breastfeeding may affect menses (33). Finally, we excluded 335 women who reported current or recent (within one year) use of oral contraception in HUNT 2 (17). Thus, 3,097 women were included in the analyses.

\section{Assessment of physical activity}

Leisure time physical activity (LTPA) was assessed in HUNT 1 by self reported questionnaire filled out at the screening station (Table 1). Based on reported intensity, duration and frequency of LTPA in HUNT 1 an index of LTPA was calculated for HUNT $1(34,35)$. With division at the $33.3^{\text {th }}$ and $66.6^{\text {th }}$ percentiles of the index, LTPA was categorized in low, moderate and high levels.

The LTPA questions have been validated for men with good test-retest reliability and validity $(36,37)$ and partly in a small sample of women (38) where a positive association was found between reported intensity and oxygen uptake during exercise.

\section{Assessment of menstrual cycle characteristics and reproductive history}

Assessment of menstrual cycle characteristics in HUNT 2 included questions such as "Do you still menstruate?", and regarding the menstruation cycle in the last 12 months; "Have your periods been regular

\begin{tabular}{|c|c|}
\hline \multicolumn{2}{|c|}{$\begin{array}{c}\text { Age } \geq 20 \text { years in HUNT 1, } \\
\leq 45 \text { years old in HUNT 2 } \\
\text { \& participated in both HUNT } 1 \text { and HUNT } 2 . \\
\mathrm{N}=5,986\end{array}$} \\
\hline \multicolumn{2}{|l|}{$\downarrow$} \\
\hline \multicolumn{2}{|c|}{$\begin{array}{l}\text { Sequential exclusion for assessing menstrual cycle } \\
\text { characteristics: }\end{array}$} \\
\hline $\begin{array}{l}\text { Very poor health in HUNT1 } \\
\text { Very functionally disabled in HUNT1 } \\
\text { Currently pregnant in HUNT } 2 \\
\text { Childbirth }<1 \text { year before HUNT } 2 \\
\text { Breastfeeding }<6 \text { months before HUNT } 2 \\
\text { Hysterectomy in HUNT } 2 \\
\text { Bilateral oophorectomy in HUNT } 2 \\
\text { Use of oestrogen tablets in HUNT } 2 \\
\text { Use of oestrogen cream in HUNT } 2 \\
\text { Current or recent use of oral contraceptives in } \\
\text { Missing all information on physical activity } \\
\text { Missing information on menstrual function }\end{array}$ & $\begin{array}{r}(\mathrm{n}=12) \\
(\mathrm{n}=33) \\
(\mathrm{n}=100) \\
(\mathrm{n}=99) \\
(\mathrm{n}=267) \\
(\mathrm{n}=97) \\
(\mathrm{n}=8) \\
(\mathrm{n}=78) \\
(\mathrm{n}=8) \\
2(\mathrm{n}=335) \\
(\mathrm{n}=469) \\
(\mathrm{n}=1,383)\end{array}$ \\
\hline Excluded total: & 2,889 \\
\hline \multicolumn{2}{|l|}{$\downarrow$} \\
\hline 3,097 women included in the $s$ & \\
\hline
\end{tabular}

Figure 1. Sequential exclusion of participants in the study of physical activity and menstrual function. ${ }^{a}$ No answer on questions needed for classification. ${ }^{\mathrm{b}}$ Including $\mathrm{n}=92$ who reported they were not sure if having regular cycles.

Table 1. Leisure time physical activity index score in HUNT 1.

\begin{tabular}{lc}
\hline Questions & $\begin{array}{c}\text { Leisure time physical } \\
\text { activity score }\end{array}$ \\
\hline Frequency of weekly $P A$ & \\
Never & 0 \\
$<1$ & 0.5 \\
1 & 1.0 \\
$2-3$ & 2.5 \\
Nearly every day & 5 \\
Intensity of $P A$ & \\
Take it easy & 1 \\
Lose breath & 2 \\
To exhaustion & 3 \\
Duration of $P A$ & \\
$<15$ minutes & 0.12 \\
$15-30$ minutes & 0.38 \\
$30-60$ minutes & 0.75 \\
$>60$ hours & 1.5 \\
\hline
\end{tabular}

Hours of leisure time activity in HUNT 1 were estimated by multiplying the activity scores for frequency and duration and this weekly duration was then multiplied by the intensity score. Thereby, leisure time physical activity index in HUNT 1 = (frequency $\mathrm{x}$ duration $\mathrm{x}$ intensity).

during the last year? (Yes, No, Unsure) (Regular means that the periods lasted about as long each time with about the same time between them)", "How many days did your period last the last time you had your period? (Number of days)", "How many days did you not bleed 
between your last period and the one before that? (Number of days)" and "Have your periods stopped for more than 3 months during the last year without you being pregnant? "and in addition "Did your periods ever stop without you being pregnant? (yes, no)" Questions also included age at menarche, current and former contraceptive use, number and timing (year) of childbirths.

We defined a short menstrual cycle as less than 24 days, normal length (eumenorrhea) as 24-34 days and long menstrual cycle (oligomenorrhea) as cycles of 35 days or more (39).

Primary amenorrhea was defined as the absence of menses by age 16 and secondary amenorrhea as the absence of three or more consecutive menstrual cycles after menarche and outside pregnancy and breastfeeding.

\section{Covariates}

Age, self assessed psychological health, education, smoking status and alcohol consumption were selfreported by questionnaire. Body mass index (BMI) was computed as $\left(\mathrm{kg} / \mathrm{m}^{2}\right)$ from measured height and weight.

\section{Statistical analysis}

Cycle length and regularity for different levels of categorical variables were compared using the chi-square test. Differences in the characteristics between HUNT 1 and HUNT 2 were compared by using the chi-square test for differences in proportions for categorical variables and the t-test for differences in means of continuous variables.

We estimated the odds of having irregular menstrual cycles, and the odds of having short cycles (as opposed to all other cycles, normal or long) and of long cycles (as opposed all other cycles, short or normal), using unadjusted and adjusted logistic regression. Parameter estimates were obtained by maximum likelihood and odds ratios (OR's) generated for irregular cycles, short cycles and long cycles with $95 \%$ confidence intervals (CIs). The association between cycle length and number of bleeding days and the physical activity variables was examined using multiple linear regression, adjusting for potential confounders. We tested for trend over levels of physical activity by assigning a value of 0,1 or 2 for low, moderate and high level, and then treated this score as continuous. If adding /removing a factor to a model changed the estimates for the physical activity factors by $10 \%$ or more, we would consider that factor as having a confounding influence and include it in the model. All two-way effect modifications were examined.

Based primarily on a priori considerations, we considered the following HUNT 1 measurements as suspected confounders: age (quartiles), smoking (never, former, current), education ( $<10$ years, 10-12 years, $>12$ years), alcohol consumption during last 2 weeks (none, 1-4 times, 5-10 times, $>10$ times), and self assessed impaired psychological health (yes, no).

Women with an unusually high or low BMI tend to have a greater frequency of menstrual cycle disruptions. Because women with high or low BMI may be less or more likely to be physically active $(40,41)$, BMI might be considered a potential confounder of the relation between LTPA and menstrual function. However, BMI can also be considered an intermediate variable in that activity could affect BMI and thereby the risk of menstrual dysfunction (42). We therefore did not include BMI as a covariate in the primary analyses because of its suspected role as an intermediate variable and its inclusion could then bias the estimated association between LTPA and risk of menstrual dysfunction. However, to assess whether inclusion of BMI affected the association with menstrual function, we subsequently conducted additional prospective and cross-sectional analyses that included BMI from HUNT 1 and HUNT 2 respectively, treating it as categorical (World Health Organization categorization of under-, normal-, and overweight and obesity) (43).

\section{Ethics}

The Norwegian Regional Committee for Medical and Health Research Ethics and the Norwegian Data Inspectorate approved the study. Permission for data handling was provided by the HUNT research group.

\section{Results}

The mean age of the study population was $28.1( \pm 3.5)$ years in HUNT 1 and $39.2( \pm 3.4)$ years in HUNT 2 $(\mathrm{p}<0.01)$. Primary amenorrhea was reported by 107 (3.5\%) women. Regular menstrual cycles were reported by $89.9 \%$ of subjects, normal cycle length by $80.4 \%$, short cycles by $5.9 \%$ and long menstrual cycles by $13.7 \%$ of the women.

The median cycle length in the whole sample was 30 days and median number of days bleeding was 5 . In women with normal cycle length, the mean cycle length was $29.3( \pm 2.8)$ and mean number of days with bleeding was $5.6( \pm 1.7)$.

Menstrual cycle length and regularity in HUNT 2 by characteristics measured in HUNT 1 are presented in Table 2.

Significant effect measure modification was found by age in the relationship between frequency of LTPA and menstrual cycle length. In the youngest age group, cycles were shortest in women with the highest reported frequency of LTPA (Figure 2) and odds of having short cycles for those who were active most days compared with those who never participated in LTPA was 3.1 (95\% CI $=0.6-16.6)$. Among women over 25 years of age, associations between LTPA and cycle length tended to be weak, and lacked statistical significance (Figure 2). Compared with low intensity LTPA, the odds of having a short cycle were lower among those with moderate intensity $(\mathrm{OR}=0.3(95 \%$ $\mathrm{CI}=0.10-0.98)$ in the youngest age group. On the 
Table 2. Characteristics of the study population in HUNT 1 and frequency of short-, normal-, and long menstrual cycles based on self-reported length of most previous cycle and regularity of menses during the last year in HUNT 2.

\begin{tabular}{|c|c|c|c|c|c|c|c|}
\hline & \multicolumn{4}{|c|}{ Cycle length N (\%) } & \multicolumn{3}{|c|}{ Regular menses N (\%) } \\
\hline & $\begin{array}{c}\text { Short } \\
<24 \text { days }\end{array}$ & $\begin{array}{c}\text { Normal } \\
24-35 \text { days }\end{array}$ & $\begin{array}{c}\text { Long } \\
35<\text { days }\end{array}$ & $\begin{array}{c}\text { Chi } \\
\text { square }\end{array}$ & Yes & No & $\begin{array}{c}\text { Chi } \\
\text { square }\end{array}$ \\
\hline Age & & & & .002 & & & .007 \\
\hline $20-25$ years & $26(3.3)$ & $641(81.1)$ & $123(15.6)$ & & $715(90.5)$ & $75(9.5)$ & \\
\hline $26-30$ years & $90(6.5)$ & $1107(79.7)$ & $192(13.8)$ & & $1267(91.2)$ & $122(8.8)$ & \\
\hline $31-36$ years & $66(7.2)$ & $743(80.9)$ & $109(11.9)$ & & $801(87.3)$ & $117(12.7)$ & \\
\hline BMI (WHO classification) & & & & .574 & & & .702 \\
\hline$<18.5$ & $9(9.1)$ & $76(76.8)$ & $14(14.1)$ & & $87(87.9)$ & $12(12.1)$ & \\
\hline $18.5-24.9$ & $141(6.0)$ & $1896(80.6)$ & $314(13.4)$ & & $2122(90.3)$ & $229(9.7)$ & \\
\hline $25-30$ & $24(5.2)$ & $371(80.5)$ & $66(14.3)$ & & $410(88.9)$ & $51(11.1)$ & \\
\hline$>30$ & $4(3.0)$ & $110(82.1)$ & $20(14.9)$ & & $122(91.0)$ & $12(9.0)$ & \\
\hline Frequency of weekly LTPA* & & & & .830 & & & .567 \\
\hline Never & $13(5.8)$ & $185(82.2)$ & $27(12.0)$ & & $205(91.1)$ & $20(8.9)$ & \\
\hline$<1$ & $67(6.6)$ & $791(78.5)$ & $150(14.9)$ & & $910(90.3)$ & $98(9.7)$ & \\
\hline 1 & $55(5.6)$ & $793(81.0)$ & $131(13.4)$ & & $872(89.1)$ & $107(10.9)$ & \\
\hline $2-3$ & $37(5.4)$ & $558(81.3)$ & $91(13.3)$ & & $621(90.5)$ & $65(9.5)$ & \\
\hline Nearly every day & $10(5.0)$ & $164(82.4)$ & $25(12.6)$ & & $175(87.9)$ & $24(12.1)$ & \\
\hline Intensity of LTPA* & & & & .168 & & & .545 \\
\hline Take it easy & $74(6.5)$ & $906(79.7)$ & $157(13.8)$ & & $1128(90.4)$ & $109(9.6)$ & \\
\hline Lose breath & $53(4.9)$ & $883(81.7)$ & $145(13.4)$ & & $962(89.0)$ & $119(11.0)$ & \\
\hline To exhaustion & $4(6.8)$ & $52(88.1)$ & $3(5.1)$ & & $53(89.8)$ & $6(10.2)$ & \\
\hline Duration of LTPA* per session & & & & .614 & & & .159 \\
\hline$<15$ minutes & $25(7.0)$ & $286(80.1)$ & $46(12.9)$ & & $318(89.1)$ & $39(10.9)$ & \\
\hline $15-30$ minutes & $46(6.2)$ & $590(79.0)$ & $111(14.9)$ & & $659(88.2)$ & $88(11.8)$ & \\
\hline $30-60$ minutes & $51(5.0)$ & $831(82.0)$ & $131(12.9)$ & & $924(91.2)$ & $89(8.8)$ & \\
\hline$>60$ hours & $15(7.0)$ & $171(79.9)$ & $28(13.1)$ & & $188(87.9)$ & $26(12.1)$ & \\
\hline$L T P A^{*}$ index & & & & .158 & & & .033 \\
\hline Low & $58(7.3)$ & $625(78.7)$ & $111(14.0)$ & & $707(89.0)$ & $87(11.0)$ & \\
\hline Moderate & $35(4.4)$ & $655(82.2)$ & $107(13.4)$ & & $731(91.7)$ & $66(8.3)$ & \\
\hline High & $38(5.8)$ & $531(81.1)$ & $86(13.1)$ & & $574(87.6)$ & $81(12.4)$ & \\
\hline Smoking & & & & .093 & & & .005 \\
\hline Never & $46(4.5)$ & $836(81.2)$ & $147(14.3)$ & & $946(91.9)$ & $83(8.1)$ & \\
\hline Former & $36(5.7)$ & $516(81.6)$ & $80(12.7)$ & & $570(90.2)$ & $62(9.8)$ & \\
\hline Current & $92(7.1)$ & $1028(79.0)$ & $181(13.8)$ & & $1143(87.9)$ & $158(12.1)$ & \\
\hline Alcohol consumption in the last & 4 days & & & .801 & & & .565 \\
\hline 0 drinks & $97(6.0)$ & $1300(80.0)$ & $228(14.0)$ & & $1465(90.2)$ & $160(9.8)$ & \\
\hline$\geq 1$ drink & $85(5.8)$ & $1182(80.9)$ & $194(13.3)$ & & $1308(89.5)$ & $153(10.5)$ & \\
\hline Education & & & & .155 & & & .132 \\
\hline$<10$ years & $50(7.4)$ & $541(79.6)$ & $89(13.1)$ & & $601(88.4)$ & $79(11.6)$ & \\
\hline $10-12$ years & $103(5.2)$ & $1589(80.4)$ & $284(14.4)$ & & $1779(90.0)$ & $197(10.0)$ & \\
\hline$>12$ years & $28(6.7)$ & $342(81.6)$ & $49(11.7)$ & & $386(92.1)$ & $33(7.9)$ & \\
\hline Poor psychological health & & & & .193 & & & .000 \\
\hline Yes & $7(11.1)$ & $47(74.6)$ & $9(14.3)$ & & $48(76.2)$ & $15(23.8)$ & \\
\hline No & $175(5.8)$ & $2444(80.6)$ & $415(13.7)$ & & $2735(90.1)$ & $299(9.9)$ & \\
\hline
\end{tabular}

*Leisure time physical activity

other hand, neither duration nor the LTPA index was strongly related with cycle length. The association of long cycles with the LTPA variables was quite weak and odds ratios close to 1 . Inclusion of BMI in the models did not affect these estimates meaningfully.

\section{Irregular cycles}

In 20-25 year old women, the odds of having irregular cycles for those participating in LTPA almost every day was nearly 5 times higher than the odds for those never participating $(\mathrm{OR}=4.7 ; 95 \% \mathrm{CI}=1.2-18.0)$.
In 26-30 year old women, the odds of having irregular cycles in those with a high level of the LTPA index compared with a low level was $1.7(95 \% \mathrm{CI}=$ 1.0-2.8).

We did not find a strong or significant association of irregular cycles with reported duration, frequency or intensity of LTPA in the oldest age group. Occupational activity was only weakly and not significantly associated with irregular menstrual cycles, irrespective of age groups. Further adjustments for BMI did not meaningfully change the above results. 


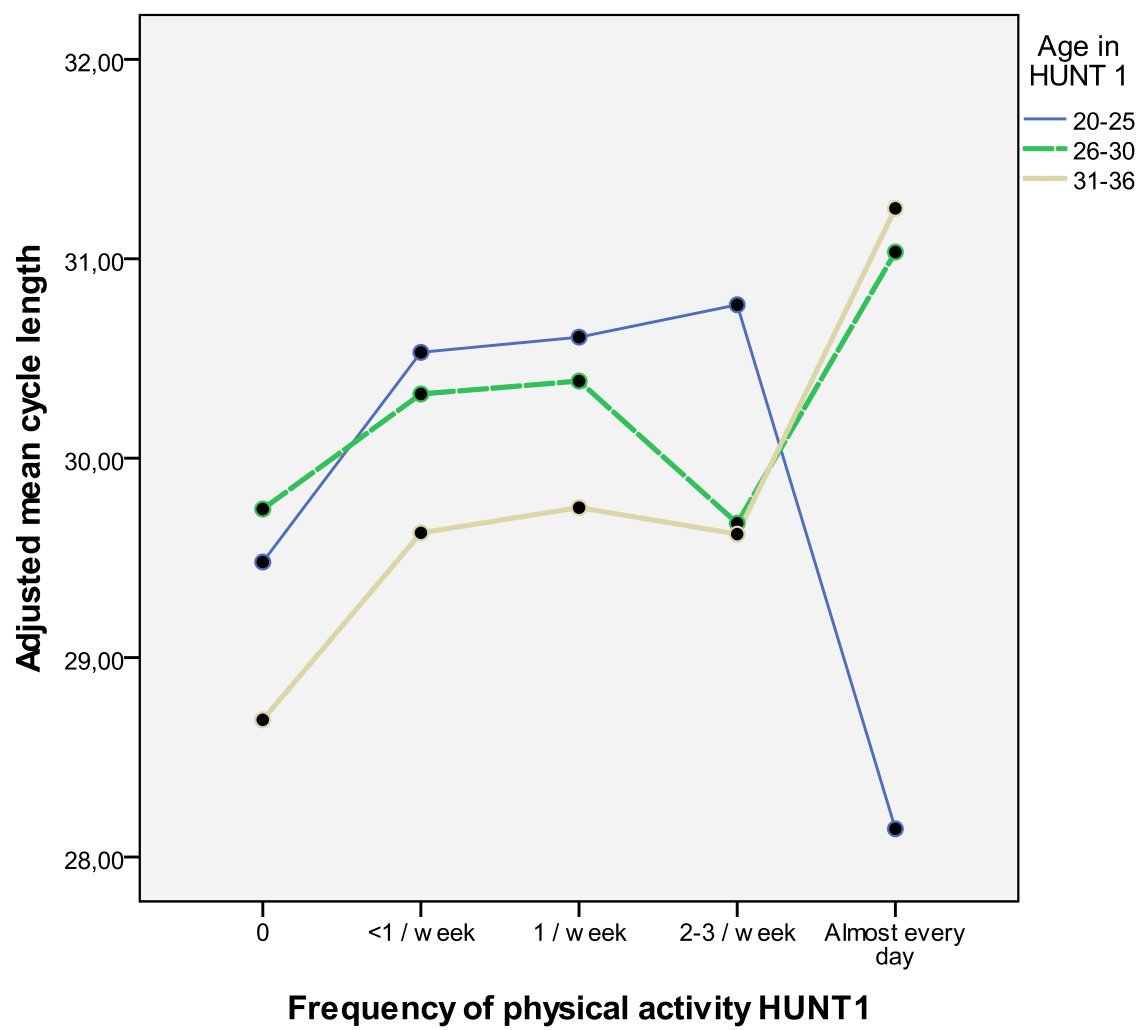

Figure 2. Mean menstrual cycle length at follow up by frequency of physical activity and age at baseline. Results adjusted for smoking and alcohol intake. Further adjustment for education did not affect the results meaningfully.

\section{Bleeding}

In the youngest women (20-25 years old at baseline), the mean number of days of menstrual bleeding tended to be lower for those with higher activity levels. However, the pattern was not monotonic, as women who reported being active on most days, had more bleeding days than those with less frequent activity participation (Figure 3).

The number of days bleeding was not found to be strongly associated with the LTPA measures in the older age groups in our sample. The relationships between bleeding and LTPA was not affected by analytic adjustment for BMI.

\section{DISCUSSION}

In this study we evaluated the longitudinal association between leisure time physical activity and menstrual cycle characteristics in healthy, premenopausal Norwegian women. Among the youngest women in our study, we observed that higher odds of irregular menstruation, shorter cycles and more bleeding days were associated with the highest frequency of LTPA. We also found some indications of a higher prevalence of irregular cycles in 26-30 year-old women in the highest LTPA index level.

Our results mostly agree with the few previous studies regarding the effect of physical activity on the menstrual cycle in the general population, were physically active women have been suggested to have longer menstrual cycles than more inactive ones $(12,16,28)$. These findings from population based studies extend on reports of higher prevalence of amenorrhea and oligomenorrhea in athletes than the general female population $(23,24)$. The subjects in the current study were older than the subjects in some of the previously published studies, and very few reported extremely high levels of physical activity. Our study did, however, include a relatively large number of women reporting no activity or very low activity levels (almost $40 \%$ reported a frequency of leisure time physical activity participation of $<1$ / week). Although we found indications of longer cycles in the more active women, risk of long cycles was not associated with activity and the observed association in our sample may not be of clinical importance. Perhaps of more concern is the observed association between higher odds ratios for irregular cycles with increasing frequency of activity. Irregular menstrual cycles may relate to anovulation, infertility and spontaneous abortion (6,9-11). A recent study has found highly active women from the HUNT studies at higher risk of infertility than moderately active ones (44).

The association between low physical activity and more bleeding days has been reported previously in some $(13,29)$ but not in all $(28)$ population based studies. The reason why young women who report being active on most days were found to have more bleeding days than less frequently active women in the same age group is unclear but some unidentified confounding 


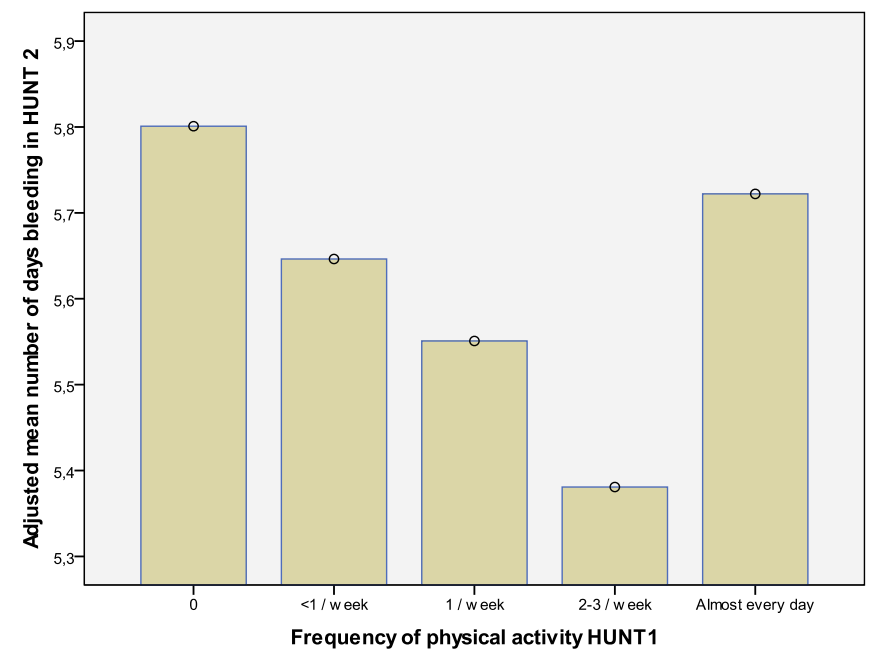

a) Mean number of days bleeding by frequency of activity $(\mathrm{p}=0.324)$.



b) Mean number of days bleeding by intensity of activity $(\mathrm{p}=0.065)$



c) Mean number of days bleeding by duration of activity per session $(p=0.039)$.

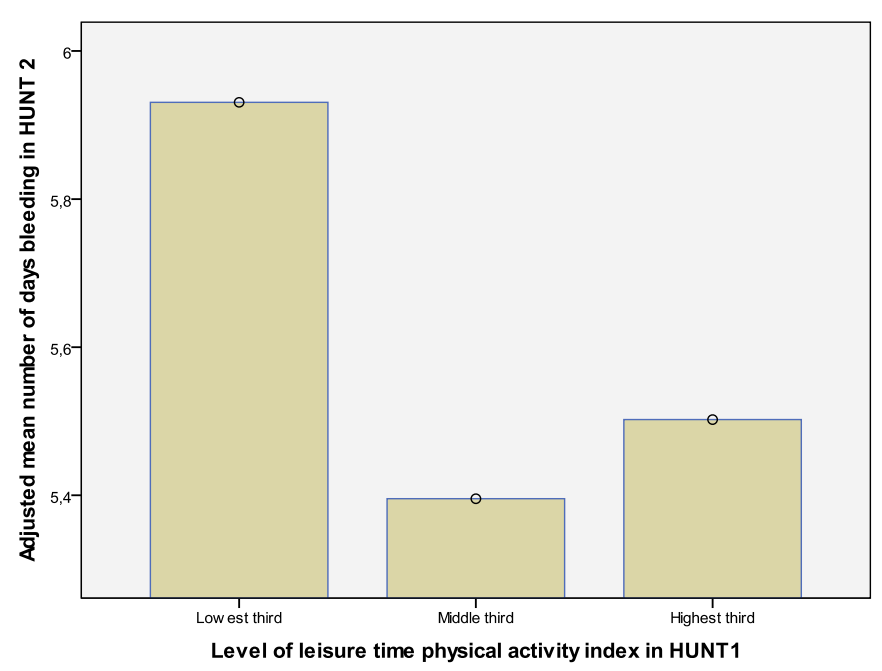

d) Mean number of days bleeding by levels of physical activity index $(p=0.007)$

Figure 3. Adjusted mean number of days bleeding reported at follow up by leizure time physical activity variables in women 20-25 years old at baseline.

factors (e.g. parity, stressful life events or body weight change) may play a role. This tendency was not reflected in the intensity, duration or LTPA index.

Menstrual disturbances in highly active women have been suggested to reflect oestrogen deficiency due to low body weight, weight loss, or excessive exercise $(25-27,45,46)$. In the current study, adjustment for BMI did not significantly alter the observed relationships between LTPA and menstrual cycle characteristics. Thus, the effect of physical activity on menstrual function may act through a mechanism that does not involve BMI to a significant extent, although it is difficult to separate direct from indirect effects (47).

The current study is population based, and it had high attendance rates. The prospective assessment of the effect of HUNT 1 physical activity on subsequent menstrual cycle characteristics hopefully contributes to avoiding potential selection bias and reporting bias of activity levels that might occur in a case-control study. However, there were possible limitations. If LTPA levels changed between HUNT 1 and HUNT 2, we would only have limited ability to estimate the effect of more recent LTPA on menstrual cycle characteristics; this could be particularly relevant if changes in LTPA have an immediate effect on menstrual function as has been suggested by previous research $(48,49)$. Although different questions were used to assess LTPA in HUNT 2, there are indications that $2-4 \%$ fewer women were inactive in HUNT 2 than in HUNT 1 (50). Even if these numbers are not large and it is possible that if measures of LTPA would have been closer in time to measures of menstrual function (HUNT 2), more subjects had reported higher activity levels and this could have affected our results. Information on 
physical activity was obtained by a self-reported questionnaire, with possible misclassification of activity by age, social-, and seasonal variations (51). By use of questionnaire, subjects may overestimate their activity levels (52). However, the HUNT questionnaires have been validated and associated with physical fitness (36-38). Also, it seems likely that any measurement error in the assessment of LTPA should not depend on menstrual status 10 years later and would often tend to bias results toward the null. In addition, if nonparticipation in HUNT 2 was jointly associated with physical activity and disturbed menstrual function, bias could have resulted. Further, we cannot exclude possible bias due to missing responses on questions regarding the menstrual cycle. In particular, a bias may be present if the subjects excluded from the analyses due to missing answers differ systematically from those who are included. Further, the cumulative effect of missing data on LTPA or menstrual cycle lead to excluding substantial number of subjects which may contribute to the weak associations found in our study.

In the current study, we focused on the overall occurrence of menstrual dysfunction in the population. Validation studies have found mean prospective cycle lengths to be longer (53) and more dispersed than the self-reported lengths, particularly in women under the age of 30 (54). Although all the women in our sample were more than 30 years of age when reporting cycle length, some misclassification may have occurred. If this misclassification did not depend upon LTPA levels, our estimates of the relationship between low
LTPA levels and long menstrual cycles may be conservative assessment of the true average. Young women that choose to live in Nord-Trøndelag (and participated in the study) are probably less like to have a higher education than those who have moved away (and therefore did not participate) and women with higher education may be underrepresented in our sample.

In summary we found that menstrual cycle length tended to increase and number of days with bleeding decrease with higher frequency, intensity and duration of leisure time activity levels. A different pattern was observed in young women in whom a high frequency of leisure time physical activity was associated with higher odds of irregular cycles, shorter menstrual cycles and more bleeding days. Although some of the effects of exercise on menstrual function may have latency period of less than 10 years, these results are in concordance with earlier findings that high levels of exercise may influence the female reproductive system and thereby affect risk of hormone-related health outcomes later in life.

\section{ACKNOWLEDGEMENTS}

The Faculty of Social Sciences and Technology Management, The Norwegian University of Science and Technology (NTNU) supported this study by a Doctoral Research Fellowship. The HUNT Study is collaboration between HUNT Research Centre (Faculty of Medicine, NTNU), NordTrøndelag County Council and The Norwegian Institute of Public Health.

\section{REFERENCES}

1. Solomon CG, Hu FB, Dunaif A, Rich-Edwards J, Willett WC, Hunter DJ, et al. Long or highly irregular menstrual cycles as a marker for risk of type 2 diabetes mellitus. JAMA 2001; 286: 2421-2426.

2. Nicodemus KK, Folsom AR, Anderson KE. Menstrual history and risk of hip fractures in postmenopausal women. The Iowa Women's Health Study. Am J Epidemiol 2001; 153: 251-255.

3. Titus-Ernstoff L, Perez K, Cramer DW, Harlow BL, Baron JA, Greenberg ER. Menstrual and reproductive factors in relation to ovarian cancer risk. Br J Cancer 2001; 84: 714-721.

4. Chavez-MacGregor M, Elias SG, Onland-Moret NC, van der Schouw YT, Van Gils CH, Monninkhof E, Grobbee DE, Peeters PH. Postmenopausal breast cancer risk and cumulative number of menstrual cycles. Cancer Epidemiol Biomarkers Prev 2005; 14: 799-804.

5. Rubba F, Mattiellob A, Chiodinic P, Celentanoe E, Galassod R, Ciardullof AV, et al. Menstrual cycle length, serum lipids and lipoproteins in a cohort of Italian Mediterranean women: Findings from Progetto ATENA. Nutr Metab Cardiovasc Dis 2008; 18: 659-663.

6. Waller K, Swan SH, Windham GC, Fenster L, Elkin EP, Lasley BL. Use of urine biomarkers to evaluate menstrual function in healthy premenopausal women. Am J Epidemiol 1998; 147: 1071-1080.

7. Fukuda M, Fukuda K, Andersen CY, Byskov AG. Characteristics of human ovulation in natural cycles correlated with age and achievement of pregnancy. Hum Reprod 2001; 16; 2501-2507.

8. Check JH, Liss JR, Shucoski K, Check ML. Effect of short follicular phase with follicular maturity on conception outcome. Clin Exp Obstet Gynecol 2003; 30: 195-196.

9. Small CM, Manatunga AK, Klein M, Feigelson H, Dominguez CE, McChesney R, Marcus M. Menstrual cycle characteristics: Associations with fertility and spontaneous abortion. Epidemiology 2006; 17: 52-60.

10. Harlow S. Menstruation and menstrual disorders: the epidemiology of menstruation and menstrual dysfunction. In Goldman M, Hatch M (eds), Women and Health. San Diego: Academic Press, 2000. 
11. Rowland AS, Baird DD, Long S, Wegienka G, Harlow SD, Alavanja M, Sandler DP. Influence of medical conditions and lifestyle factors on the menstrual cycle. Epidemiology 2002; 13: 668-674.

12. Harlow SD, Matanoski GM. The association between weight, physical activity, and stress and variation in the length of the menstrual cycle. Am J Epidemiol 1991; 133: 38-49.

13. Cooper GS, Sandler DP, Whelan EA, Smith KR. Association of physical and behavioral characteristics with menstrual cycle patterns in women age 29-31 years. Epidemiology 1996; 7: 624-628.

14. Kato I, Toniolo P, Koenig KL, Shore RE, Zeleniuch-Jacquotte A, Akhmedkhanov A, Riboli E. Epidemiologic correlates with menstrual cycle length in middle aged women. Eur J Epidemiol 1999; 15: 809-814.

15. Castillo-Martinez L, Lopez-Alvarenga JC, Villa AR, Gonzalez-Barranco J. Menstrual cycle length disorders in 18-to 40-y-old obese women. Nutrition 2003; 19: 317-320.

16. Liu Y, Gold EB, Lasley BL, Johnson WO. Factors affecting menstrual cycle characteristics. Am J Epidemiol 2004; 160: 131-140.

17. Taylor RN Jr, Berger GS, Treloar AE. Changes in menstrual cycle length and regularity after use of oral contraceptives. Int J Gynaecol Obstet 1977; 55: 55-59.

18. Jukic AMZ, Weinberg CR, Baird DD, Wilcox AJ. Lifestyle and reproductive factors associated with follicular phase length. J Women Health 2007; 16: 1340-1347.

19. Ferin M, Ferin M. Clinical review 105: Stress and the reproductive cycle. J Clin Endocrinol Metab 1999; 84: 1768-1774.

20. Barsom SH, Mansfield PK, Koch PB, Gierach G. Association between psychological stress and menstrual cycle characteristics in perimenopausal women. Women Health Iss 2004; 14: 235-241.

21. Loucks AB, Redman LM. The effect of stress on menstrual function. Trends Endocrinol Metab 2004; 15: 466-471.

22. Fenster L, Quale C, Waller K, Windham GC, Elkin EP, Benowitz N, Swan SH. Caffeine consumption and menstrual function. Am J Epidemiol 1999; 149: 550-557.

23. Russell JB, Mitchell D, Musey PI, Collins DC. The relationship of exercise to anovulatory cycles in female athletes: hormonal and physical characteristics. Obstet Gynecol 1984; 63: 452-456.

24. Otis CL, Drinkwater B, Johnson M, Loucks A, Wilmore J. American College of Sports Medicine position stand. The Female Athlete Triad. Med Sci Sports Exerc 1997; 29: i-ix.

25. Loucks AB, Verdun M, Heath EM. Low energy availability, not stress of exercise, alters LH pulsatility in exercising women. J Appl Physiol 1998; 84: 37-46.

26. Warren MP, Perlroth NE. The effects of intense exercise on the female reproductive system. $J$ Endocrinol 2001; 170; 3-11.

27. De Souza MJ, Van Heest J, Demers LM, Lasley BL. Luteal phase deficiency in recreational runners: evidence for a hypometabolic state. J Clin Endocrinol Metab 2003; 88: 337-346.

28. Sternfeld B, Jacobs MK, Quesenberry CP, Gold EB, Sowers M. Physical activity and menstrual cycle characteristics in two prospective cohorts. Am J Epidemiol 2002; 156: 402-409.

29. Harlow SD, Campbell BC. Host factors that influence the duration of menstrual bleeding. Epidemiology 1994; 5: 352-355.

30. Bouchard C, Blair SN, Bouchard C, Blair SN. Introductory comments for the consensus on physical activity and obesity. Med Sci Sports Exerc 1999; 31: S498-501.

31. Blair SN, Cheng Y, Holder JS, Blair SN, Cheng Y, Holder JS. Is physical activity or physical fitness more important in defining health benefits? Med Sci Sports Exerc 2001; 33: S379-399.

32. Warburton DE, Nicol CW, Bredin SS. Health benefits of physical activity: the evidence. CMAJ 2006; 174: 801-809.

33. Eslami SS, Gray RH, Apelo R, Ramos R. The reliability of menses to indicate the return of ovulation in breastfeeding women in Manila, The Philippines. Stud Family Plann 1990; 21: 243-250.

34. Augestad LB, Schei B, Forsmo S, Langhammer A, Flanders WD. The association between physical activity and forearm bone mineral density in healthy premenopausal women. J Women's Health 2004; 13: 301-313.

35. Augestad LB, Schei B, Forsmo S, Langhammer A, Flanders WD. Healthy postmenopausal women - physical activity and forearm bone mineral density: the Nord-Trøndelag health survey. J Women Aging 2006; 18: 21-40.

36. Kurtze N, Rangul V, Hustvedt BE, Flanders WD. Reliability and validity of self-reported physical activity in the Nord-Trøndelag Health Study: HUNT 1. Scand J Public Health 2008; 36: 52-61.

37. Kurtze N, Rangul V, Hustvedt BE, Flanders WD. Reliability and validity of self-reported physical activity in the Nord-Trøndelag Health Study (HUNT 2). Eur J Epidemiol 2007; 22: 379-387.

38. Wisløff U, Nilsen TIL, Drøyvold WB, Mørkved S, Slørdahl SA, Vatten LJ. A single weekly bout of exercise may reduce cardiovascular mortality: how little pain for cardiac gain? The HUNT study, Norway. Eur $J$ Cardiovasc Prev Rehabil 2006; 13: 798-804. 
39. Colin CM, Shushan A. Complications of menstruation; abnormal uterine bleeding. In DeCherney AH, Nathan L, Goodwin TM, Laufer N (eds). Current Diagnosis and Treatment. Obstetrics \& Gynecology. New York: McGraw Hill, 2007.

40. Godin G, Belanger-Gravel A, Nolin B. Mechanism by which BMI influences leisure-time physical activity behavior. Obesity 2008; 16: 1314-1317.

41. Mortensen LH, Siegler IC, Barefoot JC, Gronbaek M, Sorensen TIA. Prospective associations between sedentary lifestyle and BMI in midlife. Obesity 2006; 14: 1462-1471.

42. Anderssen SA, Engeland A, Sogaard AJ, Nystad W, Graff-Iversen S, Holme I. Changes in physical activity behavior and the development of body mass index during the last 30 years in Norway. Scand J Med Sci Sports 2008; 18: 309-317.

43. WHO. Obesity: preventing and managing the global epidemic. Report of a WHO Consultation. WHO Technical Report Series 894. Geneva: World Health Organization, 2000.

44. Gudmundsdottir SL, Flanders WD, Augestad LG. Physical activity and fertility in women: the NorthTrøndelag Health Study. Hum Reprod 2009; 24: 3196-3204.

45. Falk JR, Halmi KA. Amenorrhea in anorexia nervosa: examination of the critical body weight hypothesis. Biol Psychiatry 1982; 17: 799-806.

46. De Souza MJ, Toombs RJ, Scheid JL, O’Donnell E, West SL, Williams NI. High prevalence of subtle and severe menstrual disturbances in exercising women: confirmation using daily hormone measures. Hum Reprod 2010; 25: 491-503.

47. Robins JM, Greenland S. Identifiability and exchangability for direct and indirect effects. Epidemiology 1992; 3: $143-155$.

48. McTiernan A, Tworoger SS, Ulrich CM, Yasui Y, Irwin ML, Rajan KB, et al. Effect of exercise on serum estrogens in postmenopausal women: a 12-month randomized clinical trial. Cancer Res 2004; 64: 2923-2928.

49. McTiernan A, Tworoger SS, Rajan KB, Yasui Y, Sorenson B, Ulrich CM, et al. Effects of exercise on serum androgen in postmenopausal women a 12-month randomized clinical trial. Cancer Epidemiol Biomarkers Prev 2004; 13: 1099-1105.

50. Kurtze N, Gundersen KT, Holmen J. Selvrapportert fysisk aktivitet i 1980- og 1990-årene - Helseundersøkelsene i Nord-Trøndelag (HUNT). Norsk Epidemiologi 2003; 13: 171-176.

51. Vanhees L, Lefevre J, Philippaerts R, Martens M, Huygens W, Troosters T, Beunen G. How to assess physical activity? How to assess physical fitness? Eur J Cardiovasc Prev Rehabil 2005; 12: 102-114.

52. Shephard RJ. Limits to the measurement of habitual physical activity by questionnaires. Br J Sports Med 2003; 37: 197-206.

53. Jukic AMZ, Weinberg CR, Wilcox AJ, McConnaughey DR, Hornsby P, Baird DD. Accuracy of reporting of menstrual cycle length. Am J Epidemiol 2008; 167: 25-33

54. Small CM, Manatunga AK, Marcus M. Validity of self-reported menstrual cycle length. Ann Epidemiol 2007; 17: $163-170$. 